
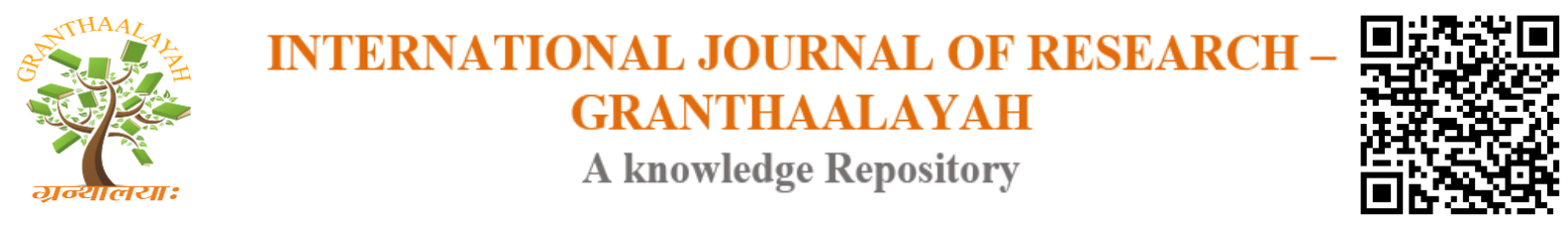

Social

\title{
EVIDENCE OF HERZBERG'S MOTIVATION-HYGIENE THEORY IN SMALL AND MEDIUM ENTERPRISES THROUGH THE LENS OF A THREE-STAR HOTEL
}

\author{
Moses Ahomka Yeboah ${ }^{1}$, Alhaji Abdulai ${ }^{2}$ \\ ${ }^{1,2}$ Department Liberal Studies, Cape Coast Polytechnic, Cape Coast, GHANA
}

DOI: https://doi.org/10.29121/granthaalayah.v4.i11.2016.2417

\section{ABSTRACT}

This paper utilized Herzberg's motivation-hygiene theory to determine the extent to which employees of Coconut Grove Hotel feel motivated and what motivational offers influence their high performance? A census approach was employed and questionnaire used to collect data from 80 employees. The data was analysed with descriptive statistics. The results show that employees experience high levels motivators and hygiene factors in their respective departments and monetary compensation had the most significant influence in spurring them to higher performance. To further boost employees' motivation, the management of Coconut grove hotel must entrenched a culture of fair treatment, respect and recognition coupled with "different strokes for different folks" approach by having regular one-on-one conversations with employees to find out what matters to them. Employees must be given greater responsibility for planning, managing and controlling their work, and also be rewarded with money for excellent job performance. Employees must be assisted to grow within their jobs and accessible opportunities for their career development.

Keywords:

Motivators, Hygiene, Performance, Hotel, Small and Medium Enterprises.

Cite This Article: Moses Ahomka Yeboah, and Alhaji Abdulai, "EVIDENCE OF HERZBERG'S MOTIVATION-HYGIENE THEORY IN SMALL AND MEDIUM ENTERPRISES THROUGH THE LENS OF A THREE-STAR HOTEL" International Journal of Research - Granthaalayah, Vol. 4, No. 11 (2016): 23-36.

\section{INTRODUCTION}

Ghana's tourism industry has seen tremendous growth in recent years. Ghana investment promotion center in 2015 intimated that the tourism industry in Ghana is witnessing an impressive turnaround due to the increasing number of tourist visits to Ghana. The World Travel and Tourism Council in its 2015 annual research on Ghana revealed that the total contribution of travel and tourism to GDP was $6.7 \%$ in 2014 and is forecast to rise by $3.8 \%$ in 2015 . Employment generation witnessed an increase of 5.5\% in 2014 and this is expected to go up by 
$2.4 \%$ in 2015. Also, visitor export accounted for $4.2 \%$ in 2014 and estimated to rise by $5.1 \%$ in 2015. Hotels have always been a primary part of tourism efforts in Ghana. Historically, Ghana's first attempt at promoting tourism was the construction of a one star hotel in 1956, furnished with 110 rooms to provide accommodation for visitors who participated in Ghana's independence celebrations in 1957 (Asiedu, 1997). The accommodation sub-sector is widely regarded as the most obvious and physical form of tourism development anywhere in the world (Mensah, 2004). Fortunately, all the accommodation types such as hostels, resorts, spas and multinational hotels are visibly operational in Ghana. The Ghana Tourism Authority has registered over 1,838 commercial accommodation facilities including hotels of different ratings in Ghana (Kelly, 2015). Notable international hotel brands operating in Ghana are; Novotel, Holiday Inn and Golden Tulip amongst others. In 2014, Ghana's hotel and restaurant sub-sector contributed 3.9\% to GDP (Ghana Statistical Service 2015). Despite the enormous contribution the hotel industry adds to Ghana's economic growth, the Ghana Hotels Association after a study concluded that services rendered by the majority of hotels in Ghana do not match international standards. Problems such as; lack of courtesy towards customers, poorly groomed employees, lack of trained chefs, poor food hygiene, limited food varieties, inadequate hotel infrastructure and safety measures were identified (Yeboah, 2015). The hotel industry has tremendous influence on the influx of tourists to Ghana since it's responsible for the accommodation needs of tourists. And as such if the aforementioned problems are not solved will derail the economic gains Ghana derives from the tourism industry. A hotel is an establishment of a permanent nature which provides visitors with shelter, food, refreshment and entertainment facilities at a price. Hotels are physical structures supported by human resources, which enable the delivery of services to its customers (Butler, 1992). Effective human resources management can be the difference between a really well run hotel and a poorly run hotel. The human resources manager can control almost the whole feeling and presence of the entire hotel. This makes the importance of human resources management for hotels very evident and imperative to employ upbeat, dedicated workers to each position. It is the job of the human resource manager to make sure that right people are chosen to work in the hotel. Motivating hotel staff not only improves job performance, but also reduces your cost associated with finding and training new workers. Employee work motivation is more central in a customer service oriented business such as the hospitality and tourism industries (Lundberg, Gudmundson \& Andersson, 2009). $\mathrm{Ng}$ and Sorensen (2008) argued that when managers recognize employees, motivate employees to work together, and eliminate obstacles thwarting effective performance, employees feel more obligated to stay with the company. Conversely put, lack of motivation among the employees of hotel establishments has many possible adverse outcomes.

\section{PROBLEM STATEMENT}

In Ghana, majority of the hotels are classified as SMEs due to the small size of their employees, this assertion is corroborated by Mensah-Ansah (2014) that many tourism accommodation facilities in Ghana can generally be classified as small firms. Hotels are part of the service industry and therefore very fundamental for hoteliers to identify factors that boost employee motivation which is imperative for business productivity and profit. Previous studies suggest that small and medium enterprises (SMEs) including hotels pay only the hourly minimum wage to their employees and other additional benefits as required by employment law, the owners of SMEs hardly provide other incentives that will make their employees happy with their jobs and 
loyal to business venture they work for (Saunders, Thornhill \& Lewis, 2002). The hotel industry as compared with other industries has no routine holidays, and the work conditions demand employees work 7 days a week and 24 hours a day coupled unattractive working atmosphere such as low pay, low job status, rigid job traits and, inadequate career advancement opportunities (Alan, Radzi \& Hemdi, 2010; Htaik \& Yih, 2011 \& Ahmand \& Zainol, 2011). The aforementioned problems have a positive resultant effect on job dissatisfaction, thus leading to increased level of turnover (Htaik \& Yih, 2011).In view to this, hotel managers must continually seek effective ways to motivate employees to keep them satisfied in order boost business performance. Hence, this paper examines what factors motivate hotel employees using Coconut Grove Hotel located at Elmina as the study hotel.

\section{RESEARCH OBJECTIVES}

1) To find out the employee motivation schemes at Coconut Grove Hotel.

2) To examine the factors that motivates employees.

3) To determine the motivational factors that influence high performance.

\section{LITERATURE REVIEW}

\section{MEANING OF MOTIVATION}

Motivation is one of the most widely studied topics in business management. However, Meyer and Becker (2004) argued that motivation is an intricate concept to be properly defined due to the many philosophical orientations explaining the nature of human beings. Nonetheless, the plethora of motivation definitions by different authors is generally similar to each other. Examples are as follows; Drummond (1990) stated motivation is embedded in the individual and helps to explain behavior. Drummond explained further that motivation is a complicated inside process with three components: what impels the individual to behave in certain ways, what controls the behavior, and what sustains the behavior. Adair (2004) defined motivation as the energetic force which is within a person that drives him or her to move forward, to achieve a goal and to make progress in a task. Kinicki and Kreitner (2001) assume that motivation triggers emotional processes that influence the encouragement and determination of intended actions that helps to attain the goals. Tella (2007) recognised motivation as the process of inspiring people to action and to achieve a desired task. From the preceding motivation definitions, it admittedly agreed by academics and experts that motivation is what drives us to pursue activities that guarantee our interest. In the domains of Self-Determination Theory, human resource management and organizational behaviour, motivation is often classified into two forms namely "intrinsic" or "extrinsic" motivation (Deci \& Ryan, 1985; Sansone \& Harackiewicz, 2000). Intrinsic motivation is the engaging in activities for its inherent enjoyment or satisfaction rather than for external consequences. Intrinsically motivated persons are driven by behaviours that guarantee them pleasure or to develop a particular skill (Reio \& Callahon, 2004). On the other hand, extrinsic motivation is derived outside an individual and it is mainly based on external outcomes like monetary compensation and reward. An extrinsically motivated person will perform a task that has satisfactory outcomes such as reward or job promotion even when they have little interest in the task (Carraher, Gibson \& Buckley, 2006). Managers need to understand the basic intrinsic and extrinsic motivators needed to inspire employees at the workplace. For 
instance, managers can intrinsically motivate employees by working with them to create challenging goals and develop a career path. As regards extrinsic motivation, Kuvaas (2006) remarked that employee's loyalty to the company is tie to pay and bonuses given to them. Also, commensurate rewards to deserving employees boost their interest to continually achieve company's objective (Burke, 2002). Reio and Callahon (2004) emphasized that extrinsic rewards motivate the employee to achieve high work efficiency. In conclusion, motivation is an imperative force at the workplace that propels people to choose a particular job, to stay with that job, and to try hard to achieve the objectives of the job.

\section{EMPLOYEE MOTIVATION IN HOTELS}

Employee motivation is very central in the development of core competences of an organization and is the factor that leads toward the competitive position of an organization. Ramlall (2004) was emphatic that for every organisation realize its goals and objective depends on the employees of that organisation and concluded that job performance is a direct result of motivation. In this light, Chand and Katou (2007) assert that hotel industry is undeniably a laborintensive industry and therefore, the growth of hotels anchors on the technical and social skills of its employees, their commitment, resourcefulness and hard work, and attitude towards assigned work. Therefore, paying attention to effectively motivate employees is fundamental in every hotel's operational success. Hotels are purposely established to meet consumers' needs for accommodation, catering and entertainment in a healthy, secure and enjoyable atmosphere (Aytaç, 2003). For this reason, hotels are admittedly service oriented business organisations. Quality is preferred over quantity as the service outcome cannot be seen nor measured by quantitative tools. Also, the actual value of the service quality at hotels as well as the perception of this fact by the consumer is significant in determining the output quality. Excellent service provided by employees can create long-lasting affirmative experiences for hotel customers. Although service quality is determined by hotel consumers, nonetheless, it is created by employees. Therefore, employees control to a greater extent the balance of final service quality. The individual motivational desires of the hotel employee play a key and perceivably a noteworthy role in achieving high satisfaction among hotel customers. This suggests that guaranteeing continuous service quality is intimately linked to employee's satisfaction. The hotel employees also have personal goals within the organization and it is generally agreed that there is cooperation and harmony between the employers and employees when both organisational and individuals goals are met. An employee whose needs are met by hotel management will increase in productivity (Aytaç, 2003). Extant research suggests organisation motivation is hardly a unitary phenomenon, because employees have not only dissimilar amounts, but also different kinds of motivation. That is, employees desire for motivation vary not only in the type of motivation, but also how much of motivation (Ryan \& Deci, 2000). Employees are motivated by many needs. These depend on many factors and differ by the person and individual situation. Managers in every type of organization have made generalized assumptions about what motivates their employees. However, to comprehend employees' needs, hotel managers should understand key theories that help them learn the basic needs of their employees (Cheng, 1995). The two pioneering theories include Maslow's theory and Alderfer's theory. Both theories emphasise the basics of human needs. Maslow (1954) stated five basic constructs form the human hierarchy of need. There are physiological needs, security needs, belongingness needs, esteem needs, and self-actualization needs. Maslow explained that lower level needs must be 
satisfied before the next higher level. When people satisfy the first level, they will go the next level and the next. Alderfer (1969) pointed out three groups of core needs: existence, relatedness, and growth. It was called ERG theory. Alderfer elucidated sometimes multiple needs could also be operating as motivators. And differing from Maslow's stance, sometimes people need the higher level before the lower level. It depends on each situation and each situation is dissimilar (Wren, 1995). Another motivational theory relevant to this study is the Herzberg's theory. Herzberg's theory is based on two divergent sets of factors that influence behavior namely hygiene and motivators. Hygiene factors consider organisational culture, policies, working condition and pay, whereas motivating factors include recognition, achievement, promotion and the intrinsic nature of the work. According Herzberg, the absence of hygiene factor with create job dissatisfaction while, existence of motivating factors at the workplace will provide job satisfaction to employees. Herzberg explained further that job satisfaction and dissatisfaction are regarded as two distinct and independent continuums. At one end, it begins from satisfaction to no satisfaction while at the other; it starts from dissatisfaction to no dissatisfaction. And concluded that hygiene factors induce employees extrinsically while, motivating factors offer employees with intrinsic value. Quite a number of studies that were carried out in the past to find out the factors that motivate hotel employees reported varied outcomes. For instance, Kovach (1987) concluded after forty years of study that good wages ranked the first through the fifth of the ten items of motivational factors and in 1992, Charles and Marshall corroborated Kovach' research that good pay is the topmost motivating factor for employees. However, Siu, Tsang and Wong (1997) conducted a study of 1,245 employees of Hong Kong hotels and their findings suggested that an opportunity for advancement is the first factor motivating employees, while good pay recorded the third position. Balmer and Baum (1993) used Herzberg's theory to find out the factors that accounted for hotel guest satisfaction in Cyprus. And they affirmed that Herzberg's theory is more appropriate and germane than Maslow's theory in view of changes in customer expectations and the concept of quality. Hence, this study adapted the Herzberg's motivation-hygiene theory as the underpinning motivational theory.

\section{METHODOLOGY}

Coconut Groove hotel is located in Elmina. Elmina is a town and the capital of the Komenda/Edina/Eguafo/Abirem District on the south coast of South Ghana in the Central Region. Coconut Groove Beach Resort started operation in 1994 and it is under the management of Groupe Nduom. The hotel runs seven departments with the following services; free Wi-Fi in all rooms, 24-hour front desk and room service, facilities for disabled guests, car park and luggage storage. The hotel has 67 rooms including suites. The hotel's recreational facilities, which include hot tub, private beach, fitness center, golf course (on site), and outdoor pool are designed for escape and relaxation. Coconut Grove Hotel has a total number of 102 employees. Table 1 indicates the employee size in each of the seven departments.

Table 1: Distribution of Employee size in the Departments

Departments

Housekeeping

Maintenance

Front office

Food \& beverage
Employee size

25

12

6

26 


$\begin{array}{lc}\text { Stores } & 4 \\ \text { Transport } & 6 \\ \text { Grounds and Golf } & 23 \\ \text { Total } & 102\end{array}$

A census approach was employed and questionnaire used to collect the data. The items on the questionnaire were developed by reviewing extant literature on Herzberg's motivation theory. The questionnaire was made up of 28 items grouped into two sections. The first section elicited information on the demographics of the employees. Section two was subdivided into three parts to garner information on employee motivation. Part I and II sought data on motivators and hygiene factors. Part III on factors that motivate employees as well as influence their high performance. A Likert scale of 5-points was used. Out of the 102 employees, 80 participated making the response rate $78.43 \%$. The data was analysed with descriptive statistics.

\section{RELIABILITY TEST}

The Cronbach's coefficient alpha $(\alpha)$ was used to determine the reliability coefficient of the hygiene and motivator factors.

Table 2: Cronbach's Alpha Coefficients

Motivation Factors Number of items

Hygiene

Motivators

7

7
Cronbach Alpha

.771

.787

Source: Field data, 2016.

From table 2, the Cronbach alpha values for both hygiene and motivators factors were higher than 0.7 , hence reliable to use as propounded by Fraenkel and Wallen (2000) that a Cronbach's alpha greater than 0.7 is reliable.

\section{RESULTS AND DISCUSSION}

\section{EMPLOYEES PROFILE}

The female employees dominated with $61.3 \%$ whereas their male counterpart recoded $38.8 \%$. Employees between the ages of 40-49 were the majority with $47.6 \%$. Followed by $20-29$ with $25.1 \%$ and age bracket of 50-59 had $11.3 \%, 30-39$ recorded $8.8 \%$ and the least age group of $7.5 \%$ were above 60 years. As regards educational qualification, 6.3\% has Postgraduate degree, $11.3 \%$ with Bachelor degree, 55.1\% completed senior high school, while $22.5 \%$ attended Commercial/Vocational/Technical school. Quite surprisingly $4.8 \%$ have never been to school. These outcomes show that majority of the workforce are not very schooled. $62.4 \%$ confirmed they have had previously worked in another hotel before joining Coconut Grove Hotel, whereas $37.4 \%$ have no such prior hotel work experience. $58.8 \%$ have being with the hotel at most five years and $41.2 \%$ above five years. 


\section{EMPLOYEE MOTIVATION AT COCONUT GROVE HOTEL}

The first objective was to find out the extent to which employees of Coconut Grove hotel experience hygiene and motivator factors in their work. The presence of these factors was measured on mean scale of 1 to 5, with 1-2.9 indicating low motivation, while 3-5 indicates high motivation.

Table 3: Motivators

\begin{tabular}{lc} 
Statements & Mean* \\
\hline Implements policies with fairness and equity & 3.63 \\
Training and development opportunities & 3.62 \\
Possibility to be promoted & 3.45 \\
Recognition of workers contribution & 3.44 \\
Work match with skills and abilities & 3.42 \\
Job beneficial to career & 3.41 \\
Opportunities for achieving personal goals & 3.37 \\
Overall Mean & 3.47 \\
\hline
\end{tabular}

*Scale (Mean): 1-2.9 = low and 3-5= high.

Source: Field data, 2016.

The findings depicted in Table 3 indicate that employees experience high level of motivators at work with a mean score of 3.47. In particular, $78 \%$ of the employees admitted that policies implemented the management are fair and equitable. This means employees enjoy equality in the workplace and each one has the same chance of taking advantage of opportunities to develop their skills. This is reaffirmed by $77.5 \%$ of the employees acknowledging that training and development opportunities are justly available. Also, majority [80\%] of the employees agree that promotion opportunities are merit-based and that provide motivation for increased productivity. Employees recognize that the best performers are the ones who get ahead and as such may put forth the extra effort they believe it takes to receive promotions. The employees intimated that management appreciates their good work; hence they feel satisfied and inspired to maintain or improve their good work. This brings to the fore, the importance of praise and recognition as essential motivational tools for encouraging outstanding performance at the workplace. Employees desire to be respected and valued for their contribution. Everyone wants a 'pat on the back' to make them feel good. As regards work match with skills and abilities, $83 \%$ of the employee affirmatively agreed. This outcome projects a good image about the human resource management system at Coconut Grove hotel because some labour mismatch is unavoidable, as the labour market entails multifaceted decisions by employers and workers, and depends on many external factors. But high and continual skills disparity is costly for employers, workers and society at large. Empirical studies suggest a dramatic boost in both worker and business performance when an organization effectively sets and closely matches individual employee goals to the company's overall strategy. Amazingly, $79 \%$ of the employees admitted that their personal goals tie with the Hotel's goal and thus good news because it create a corporate atmosphere of shared responsibility that will drive the success of the hotel. 
Table 3: Hygiene Factors

Statements Mean*

Happy with the incentives provided

3.56

Provision of commensurate salary

The boss is good at communication

3.19

Soliciting views from workers

3.16

Satisfied with the working condition

3.14

Provision of needed resources for work

3.13

Promotion based on performance

3.00

Overall mean

*Scale (Mean): 1-2.9 = low and 3-5= high.

Source: Field data, 2016.

The recorded overall mean of hygiene factors present at Coconut Grove hotel was 3.2 and this clearly suggests that the employees are highly not dissatisfied with the hygiene-driven motivation provided by management. Simply put, adequate or reasonable hygiene factors are available at Coconut grove hotel to pacify the employees from becoming dissatisfied. For instance, $73.8 \%$ of the employees confirmed their happiness with the incentives, while $86.2 \%$ agreed they receive commensurate salary. Nothing influences employee morale as much as individuals who feel they are poorly paid in comparison with others based on their contribution and that of other similar jobs. As regards the flow of communication between superiors and subordinates, $67.5 \%$ of the employees' concurred good communication systems exist at the workplace as well as $71.2 \%$ admitted their views are elicited and considered in decision making. These outcomes augur well for the hotel because effective verbal and nonverbal communication skills are valuable in the workplace. Understanding the benefits of effective communication enables companies to concentrate on building a workforce that is able to communicate within the firm and with customers, vendors and international business partners. Employees spend a huge proportion of their lives at work, so naturally it is important that they have a good environment to work in. The effects of work atmosphere on all aspects of a person's well-being are much further-reaching. However, 59.9\% and $60 \%$ of the employees were dissatisfied with working conditions and available resources at the workplace respectively. This is not a good situation for the hotel in that a bad work environment does not only cause employees to be unhappy with their jobs, but it makes them less productive and exposes them to making mistakes. Aside from the effect on the business, several studies have found that poor working conditions can cause continuing health problems including stress, depression and anxiety. Promotion is made either on the basis of seniority or on the basis of merit or both. In the case of Coconut grove hotel, $52.5 \%$ of the employees have the same opinion that management prefers merit-based promotion and the advantage with this preference is that since efficiency and talents are rewarded, it encourages the employees to improve their knowledge in sustaining a high level of productivity.

\section{FACTORS THAT MOTIVATE EMPLOYEES}

The second objective sought to determine the factors that motivate employees. These factors were broadly categorised into three. The first factor is work condition [Company policies, resources, work schedule, job security and work safety \& leadership style]. Followed by staff development [Training, promotion \& adequate job responsibility] and the third factor is money 
[Salary, bonuses \& incentives]. The Bar chart below illustrates the opinions of employees expressed in percentages regarding each of these motivational factors.

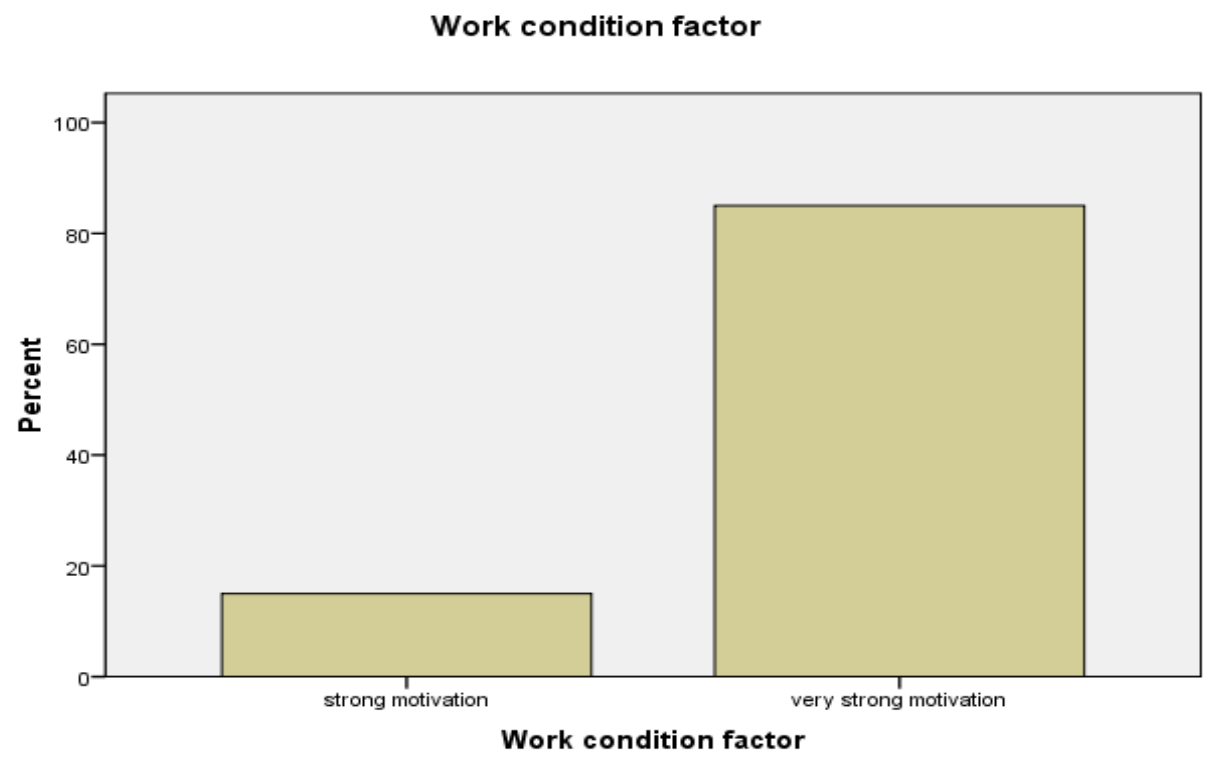

Figure 1: Work condition

From figure1, the Bar chart revealed that $85 \%$ of the employees affirmed the prevailing conditions at the workplace were very strong motivators, whereas $15 \%$ was attributed to employees who recognised work conditions as strong motivator. Conversely put, none of the employees discounted the effect of the work environment in motivating them. This implies that employees recognize a conducive work environment such as safety, job security, good rapport with co-workers, appreciation for good performance and participation in the decision making process of the firm as important motivational tools. This argument aligns with Bakotic and Babic (2013) that employees working under difficult conditions are dissatisfied. And, they concluded that employees increase their level of commitment once they realize that the firm considers them important. Organizational policies can have varying impacts on employee motivation levels. For example, highly bureaucratic and well-structured organizations typically follow a culture with extensive controls, whereas collaborative culture presents decentralized employees with integrated units working collectively to find solutions to problems. The earlier result of $71.2 \%$ of the employees admitting their views are considered in decision making clearly indicates that presence of the latter form of organisational culture at the hotel. The inference is that the management of Coconut grove hotels has created a communicative company culture that gives employees opportunities to be innovative, assigned roles in which they can succeed, and also build meaningful relationships with managers and co-workers. This type of culture leads employees to greater participation, creativity and innovation. 


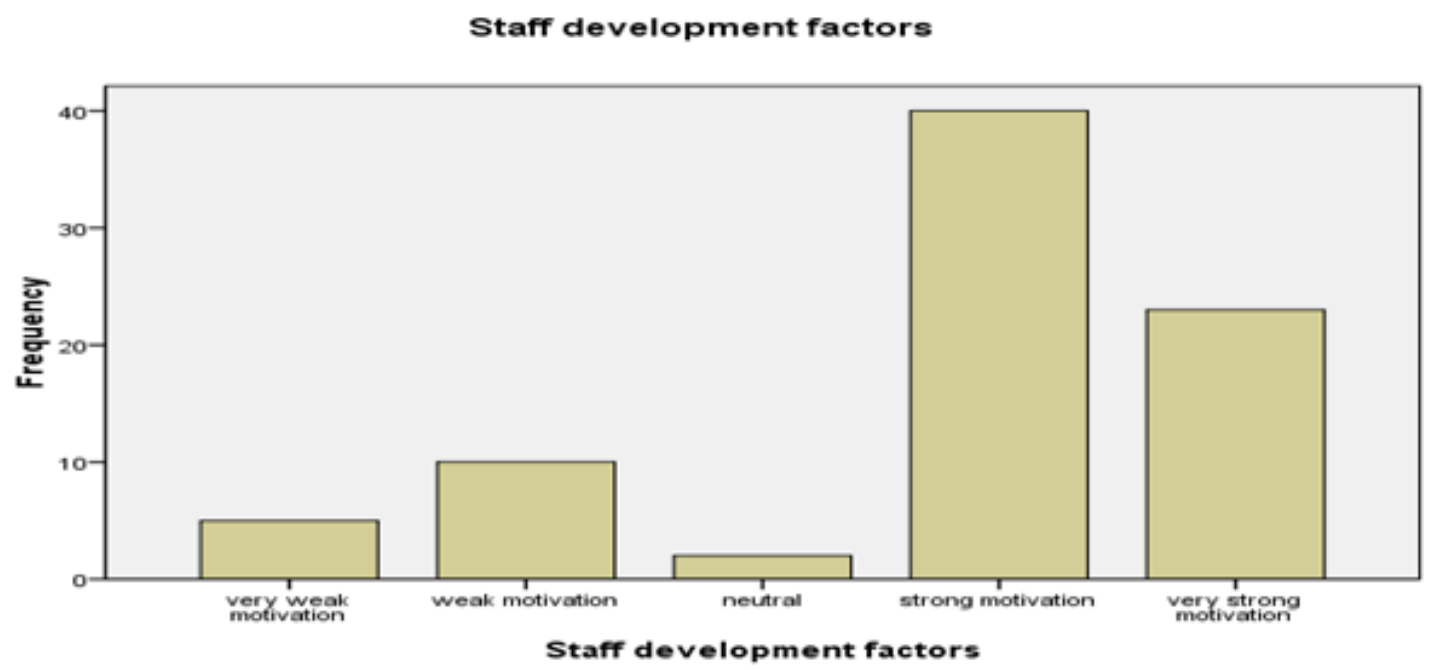

Figure 2: Staff Development

As regards the extent of motivation employees derive from available staff development opportunities [Figure 2], 50\% indicated strong motivation, $28.8 \%$ as very strong motivation, $12.5 \%$ recorded weak motivation, while $6.2 \%$ answered very weak motivation. $2 \%$ of the employees were indifferent about their career development opportunities. The overall impression that can be drawn from these results is that majority of the employees (78.8\%) recognize the significance of opportunities to develop themselves as key motivation. Employee development opportunities are imperative since employees are the true assets of very organization. Employees need to develop their knowledge and skills often to keep themselves abreast with the latest developments to survive the fierce competition in the job market. Employee development activities and trainings enhance their skills and upgrade their existing knowledge in order to perform better. Employee development is significant not only for professional but also personal growth of employees. Employees inculcate sense of pride and commitment when they feel that their organization is investing time and resources to train them. The management of Coconut grove hotel can employ in-house and outsourced trainings, conferences and seminars to develop and make employees better and reliable resources. This will indeed enable employees to maximise their performance and eventually benefitting the organization by yielding higher profits.



Figure 3: Money 
The results in figure 3 clearly show that monetary factors have a very strong motivation on employees with $67.5 \%$ of them affirming that. $23.8 \%$ recognise money as strong influence, $7.5 \%$ of the employees were unmoved by the motivational potency of money as well as $1.2 \%$ regarded money as weak motivator. This outcome is not surprising because the motivational effect of money is far-reaching. Money appeals to all demographics and can used as an effective way to motivate lowest grade employee all the way to the head of the organisation. Money is central in motivating employees. Managements often times offer financial incentives such as wages and salaries, bonus, health insurance, medical reimbursement, retirement benefits etc. to motivate employees. Money enables the fulfillment of the social needs of employees to some extent for the reason that money is often regarded as a basis of status, respect and power. Although the motivational influence of money is widely agreed upon by scholars and human resource management experts, money will not always be a motivating factor to all employees, no wonder $1.2 \%$ of employees of Coconut grove hotel regarded money as a weak motivator. Some people argue that only the prospect of receiving money in the near future is a strong enough motivator to influence behavior. Once the employee receives the money, its power to influence behaviour ends immediately. They concluded that rewards that are solely monetary will stifle employee's creativity and unique approach in performing assigned job. Pure monetary gain takes the "interesting factor" out of a job. Therefore, organisations should be cautious of employing money exclusively to motivate staff, as this scheme may sooner or later lose its effectiveness and employees may begin to think that money is most valued than anything else.

\section{MOTIVATIONAL FACTORS THAT INFLUENCE HIGH PERFORMANCE}

The third objective was to examine the factors that motivated employees to increase their performance on the job. The factors include; conducive work atmosphere, resources, assistance from colleagues, career development opportunities and money. The employees were required to indicate the aforementioned factors that motivated them to high performance. what factor [s] influence your high perfomance

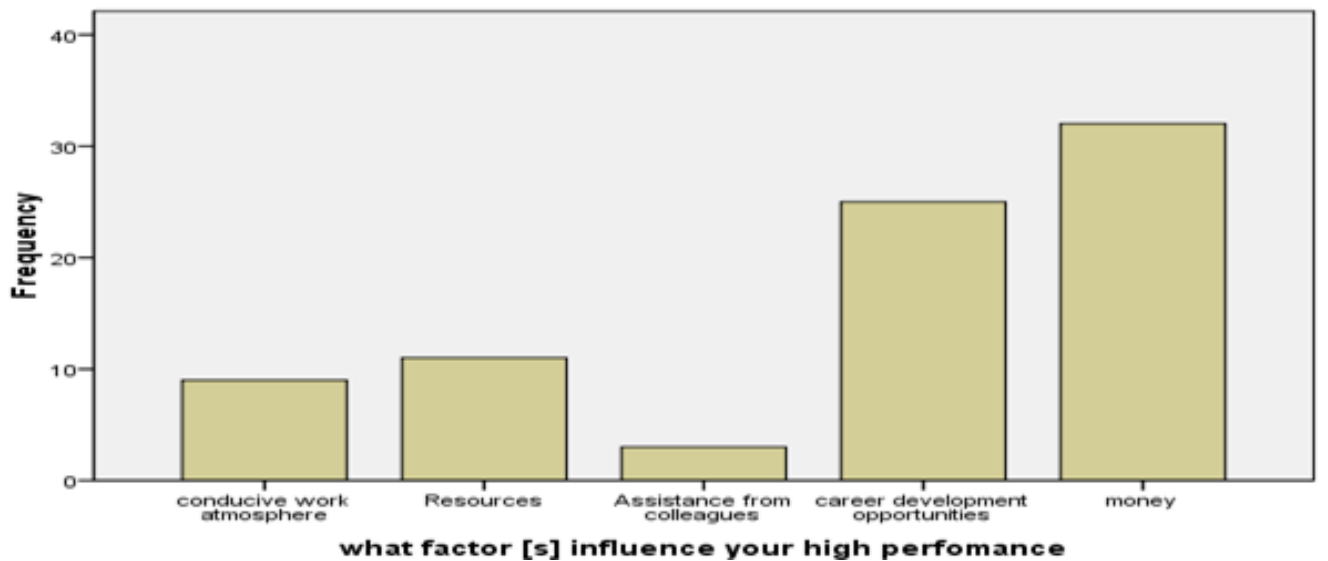

Figure 4: What factor[s] influence employee high performance

The majority of the employees [40\%] indicated that monetary compensation had the most significant influence in spurring them to higher performance [Figure 4]. This outcome is not surprising because people including employees are often motivated by money. Employees view their monetary remuneration as the value employers place on their work and this mindset greatly influence their performance. Employees earning salary are likely to perform to their potential if 
they are happy with the amount. A worker is much more enthusiastic to put in extra hours at the workplace if he/she feels the financial rewards are a fair trade-off. Well-paid employees feel valued by their organization and remain loyal to the organisation, whereas employees who don't feel like their organization is paying them a high enough salary are much more inclined to look for and accept a higher paying position of a similar nature at another company. Next, $31.2 \%$ of employees preferred available career development opportunities to boost their performance. Contemporary employees are enthusiastically concerned about their work performance and are increasingly conscious of the accelerated obsolescence of knowledge and skills in this rapidly changing work environment. Employees exposed to frequent training and development programmes will become more abreast with modern skills and knowledge. The availability of resources at work productively influences $13.8 \%$ employees. And 11.2\% of the employees increase their performance in the midst of a favorable work environment. The workplace environment impacts employee morale and productivity both positively and negatively. Employees working in bad or unsafe environment [poorly designed workstations, inappropriate lighting, lack of ventilation, unsuitable furniture, and insufficient safety measures in fire emergencies, excessive noise and lack of personal protective equipment] are prone to occupational hazard and, thus productivity is decreased. Experts argue that the quality of the employee's workplace environment greatly impacts on their level of motivation and subsequent performance. And, hence recommend that effective team behaviors among employees can tremendously increase performance when organizations face new challenges. They remarked employees assisting each other at work are a key driving force for improving a firm's performance. However, an infinitesimal number of employees [3.8\%] admitted their performance is enhanced by the assistance received from their colleagues. This connotes the absence of collaborative work culture among the employees of the hotel, despite the widely accepted consensus that teamwork is integral mean of improving man-power utilization and potentially increasing performance of employees. In fact, Sparrow (2003) argued that teamwork may impact positively on organisation performance, job satisfaction and increased employee commitment level.

\section{CONCLUSION}

The results show that employees of Coconut Grove hotel experience high levels motivators and hygiene factors in their respective departments. Also, monetary compensation had the most significant influence in spurring employees to higher performance. Thumbs-up to the management of the hotel for navigating the difficult path of promoting job satisfaction as well as reducing job dissatisfaction among employees and making them feel a sense appreciation and motivation. To further enhance the presence of these motivational factors in the work environment, the paper recommends that the management of Coconut grove hotel must approach motivating its employees in a very general way. First, the management must employ "different strokes for different folks" - in other words, employees will perceive the same work-related issues and situations differently, and will be motivated by dissimilar offers. The surest way is for hotel managers to have regular one-on-one conversations with employees to find out what matters to them. Next, managers must rid the organisation and workplace of things that are annoying to employees. A culture of respect, recognition and fair treatment must be entrenched. Once employees have the sense of the preceding cultural climate in the workplace, hotel managers must engage employees with greater responsibility for planning, managing and 
controlling their work. Also, employees must be recognised and rewarded with money for excellent job performance, assisted to grow within their jobs and accessible opportunities for their career development.

\section{REFERENCES}

[1] Adair, J. (2004). Adair on team building and motivation. Pp1-119. Retrieve, from http://uploading.com/files/get/YLRDCEJY/Retrieved 25, March, 2015

[2] Ahmad, R. \& Zainol, N. Z. (2011). What it takes to be a manager: The case of Malaysian five star resort hotels. 2nd International Conference on Business and Economic Research (2nd Icber 2011) Proceeding.

[3] Alan, S. Z. R., Radzi, S. M. and Hemdi, M. A., 2010. An empirical assessment of hotel managers turnover intentions: the impact of organizational justice. Journal of Tourism, Hospitality \& Culinary Arts, pp. 1-22.

[4] Alderfer, C.P. (1969) 'An Empirical Test of a New Theory of Human Needs', Organizational Behaviour and Human Performance, 4: 142-75.

[5] Asiedu, A. B. (1997). Prospects for an emerging tourism industry in Ghana. Research Review (NS), 13, 1-12.

[6] Aytac Serpil (2003). Calisma Psikolojisi Alannada Yeni bir

[7] Balmer, S. and Baum, T. (1993). Applying Herzberg's Hygiene Factors to the Changing Accommodation Environment. International Journal of Contemporary Hospitality Management, 5 (2), 32-35.

[8] Burke, W.W. (2002). Organizational Change: Theory and Practice. Sage: Thousand Oaks.

[9] Butler, R. (1992). What young people want to know when: Effects of mastery and ability goals on interest in different kinds of social comparisons. Journal of Personality and Social Psychology, 62, 934-943.

[10] Carraher, R, Gibson, A. \& Buckley R (2006). Compensation in the Baltic and the USA, Baltic Journal of Management Vol. 1, pp 7-23.

[11] Chand, M. and A. A. Katou (2007) the impact of HRM practices on organizational performance in the Indian hotel industry, Employee Relations, 29 (6), 576-594.

[12] Charles, K. R., and Marshall, L. H. (1992). Motivational preferences of Caribbean hotelworkers: An exploratory study. International Journal of Contemporary Hospitality Management, 4(3), 25-29.

[13] Cheng, H. (1995). An Assessment of the Importance of Employee Motivation in the Hotel Industry in Taipei, Taiwan. Unpublished Master's Thesis, University of Wisconsin-Stout, Menomonie, Wisconsin, United States 60. Available online at: http://www.univ.wis-steducl accessed on [25/09/2013].

[14] Deci, E. L., \& Ryan, R. M. (1985). Intrinsic motivation and self-determination in human behavior. New York: Plenum.

[15] Drummond, K. E. (1990). Human Resource Management for the Hospitality Industry. New York, NY: Van Nostrand Reinhold.

[16] Ghana Statistical Service (2014). Gross Domestic Product. National Account Statistics.

[17] Kelly, J. (2015). Hotel Industry in Ghana Falls Under Standards. Newsghana.com.gh.

[18] Kreitner, R., \& Kinicki, A. (2001), Organisational Behaviour, 5th ed., McGraw- Hill, New York, NY. 
[19] Kovach, K. A. (1987). What motivates employees? Workers and supervisors give different answers. Business Horizons, 30. 58-65.

[20] Kuvaas, B. (2006). Work performance, affective commitment and work motivation: The roles of pay administration and pay level. Journal of Organizational Behavior, 27(3), 365-385.

[21] Saunders M, Thornhill A, Lewis P. (2002) 'Understanding employees' reactions to the management of change: an exploration through an organisational justice framework'. Irish Journal of Management, 23 (1), pp. 85-108.

[22] Lundberg, C., Gudmundson, A., Andersson, T.D. (2009). Herzberg's Two-Factor Theory of work motivation tested empirically on seasonal workers in hospitality and tourism, Tourism Management 30,890-899.

[23] Maslow A. H. (1954).Theory of Human Motivation: Chicago, IL: John Wiley \& Sons.

[24] Mensah, S. (2004). A Review of SME Financing Schemes in Ghana. Paper Presented at the UNIDO Regional Workshop of Financing Small and Medium Scale Enterprises, Accra, Ghana, 15 - 16 March 2004.

[25] Mensah-Ansah, J. (2014). Small tourism accommodation business owners in Ghana: a factor analysis of motivations and challenges. African Journal of Hospitality, Tourism and Leisure Vol. 3 (1).

[26] Ng, T., W., H., and Sorensen, K., L., 2(008). Toward a Further Understanding of the Relationships between Perceptions of Support and Work Attitudes - A Meta-Analysis. Group and Organization Management, 33(3), 243-268.

[27] Ramlall, S. (2004). A review of employee motivation theories and their implications for employee retention within organizations. The Journal of American Academy of Business, Cambridge, 5 (1/2), 52-63.

[28] Reio, T. G., Jr., \& Callahan, J. (2004). Affect, curiosity, and socialization-related learning: A path analysis of antecedents to job performance. Journal of Business and Psychology, 19, 3-22.

[29] Ryan, R. M., \& Deci, E. L. (2000). Self-determination theory and the facilitation of intrinsic motivation, socialdevelopment, and well-being. American Psychologist, 55, 6878.

[30] Sansone, C. and Harackiewicz, J.M. (2000). Intrinsic and Extrinsic Motivation: The Search for Optimal Motivation and Performance. San Diego, CA: Academic Press.

[31] Siu, V., Tsang, N., Wong, S. (1997). What motivates Hong Kong's hotel employees? The Cornell Hotel and Restaurant Administration Quarterly, 38(5), 44-49.

[32] Tella, A. (2007). The Impact of Motivation on Students' Academic Achievement and Learning Outcomes in Mathematics amongSecondary School Students in Nigeria. Eurasia Journal of Mathematics, Science and Technology Education, 3(2), 149-156.

[33] Wren, J. T. (1995). The Leader's Companion: Insights on Leadership Through the Ages. New York, NY: The Free Press.

[34] Yeboah, A.M. (2015). Determinants of SME Growth: An Empirical Perspective of SME in the Cape Coast Metropolis, Ghana. The Journal of Business in Developing Countries, Vol. 14.

[35] Wan-Yih, W. \&Htaik, S. (2011).The Impacts of Perceived Organizational Support, Job Satisfaction, and Aorganizational Commitment on Job Performance in Hotel Industry. The 11th International DSI and the 16th APDSI Joint Meeting, Taipei, Taiwan, 12 - 16. 